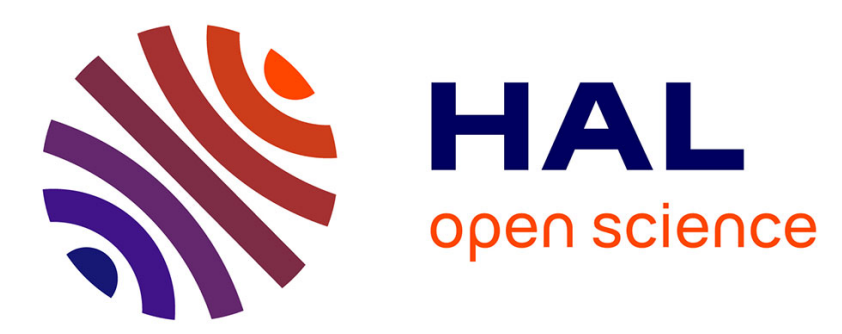

\title{
Optimal Transition from Coal to Gas and Renewable Power under Capacity Constraints and Adjustment Costs
}

Oskar Lecuyer, Adrien Vogt-Schilb

\section{To cite this version:}

Oskar Lecuyer, Adrien Vogt-Schilb. Optimal Transition from Coal to Gas and Renewable Power under Capacity Constraints and Adjustment Costs. 2014. hal-01057241

\section{HAL Id: hal-01057241 \\ https://hal-enpc.archives-ouvertes.fr/hal-01057241}

Preprint submitted on 21 Aug 2014

HAL is a multi-disciplinary open access archive for the deposit and dissemination of scientific research documents, whether they are published or not. The documents may come from teaching and research institutions in France or abroad, or from public or private research centers.
L'archive ouverte pluridisciplinaire HAL, est destinée au dépôt et à la diffusion de documents scientifiques de niveau recherche, publiés ou non, émanant des établissements d'enseignement et de recherche français ou étrangers, des laboratoires publics ou privés. 


\title{
Optimal transition from coal to gas and renewable power under capacity constraints and adjustment costs
}

\author{
Oskar Lecuyer ${ }^{1}$, Adrien Vogt-Schilb ${ }^{2,3}$ \\ ${ }^{1}$ Department of Economics and Oeschger Centre for Climate Change Research, University \\ of Bern, Bern, Switzerland \\ ${ }^{2}$ The World Bank, Climate Change Group, Washington D.C., USA \\ ${ }^{3}$ CIRED, Nogent-sur-Marne, France
}

\begin{abstract}
This paper studies the optimal transition from existing coal power plants to gas and renewable power under a carbon budget. It solves a model of polluting, exhaustible resources with capacity constraints and adjustment costs (to build coal, gas, and renewable power plants). It finds that optimal investment in renewable energy may start before coal power has been phased out and even before investment in gas has started, because doing so allows for smoothing investment over time and reduces adjustment costs. Gas plants may be used to reduce short-term investment in renewable power and associated costs, but must eventually be phased out to allow room for carbon-free power. One risk for myopic agents comparing gas and renewable investment is thus to overestimate the lifetime of gas plants - e.g., when computing the levelized cost of electricity - and be biased against renewable power. These analytical results are quantified with numerical simulations of the European Commission's 2050 energy roadmap.
\end{abstract}

Keywords: climate change mitigation; path dependence; optimal timing; investment; resource extraction; dynamic efficiency; early-scrapping;

JEL classification: Q54, Q58

Many governments aim at stabilizing climate change to avoid important climate damages, which requires reaching near-zero greenhouse gas (GHG) emissions in the long term (Collins et al., 2013; Steinacher et al., 2013). Abating GHG emissions from power generation is key to reach this goal, as the power sector is currently responsible for nearly $40 \%$ of carbon emissions worldwide, and fuel switching to clean electricity is a major technical option to reduce

Email addresses: oskar.lecuyer@vwi.unibe.ch (Oskar Lecuyer), avogtschilb@worldbank.org (Adrien Vogt-Schilb)

We thank Mook Bangalore, Céline Guivarch, Louis-Gaëtan Giraudet, Stéphane Hallegatte, Jean-Charles Hourcade, Guy Meunier, Jean-Pierre Ponssard, Antonin Pottier, Philippe Quirion, Julie Rozenberg, François Salanié, Ralph Winkler and one anonymous referee from the FAERE Working Paper series for useful comments and suggestions on earlier versions of this paper. We are responsible for all remaining errors. We are grateful to Patrice Dumas for technical support, and to Institut pour la Mobilité Durable (Renault and ParisTech), École des Ponts ParisTech and EDF R\&D for financial support. The views expressed in this paper are the sole responsibility of the authors. They do not necessarily reflect the views of the World Bank, its executive directors, or the countries they represent. 
emissions from other sectors (Williams et al., 2012; Kriegler et al., 2014).

Two important features of the electricity sector are that (i) it depends on long-lived capital that in general is tied to a specific fuel, and (ii) today's power production greatly relies on polluting fossil fuels such as coal (IEA, 2014). Several alternatives are thus available to abate GHG emissions from electricity production. Emissions may be reduced by replacing coal plants with new gas power plants ${ }^{1}$ or with more-expensive but almost-carbon-free options such as renewable power. Also, decision makers can either wait for existing plants to reach their natural lifetime, or decide to decommission them earlier in order to switch faster to cleaner energy sources.

This paper analyzes the optimal timing of investment made to transition from coal power to gas and renewable power under a carbon budget. To our knowledge, it proposes the first theoretical model capable of investigating this question, as related issues have been treated in separate strands of the analytical literature.

On the one hand, a strand of the literature studies the optimal usage of different fossil fuels through the lens of nonrenewable resources theory (Hotelling, 1931; Herfindahl, 1967), with little attention to the dynamics of capital accumulation (Chakravorty et al., 2008; Smulders and van der Werf, 2008; van der Ploeg and Withagen, 2012). For instance, Chakravorty et al. (2008) find that a carbon price may accelerate the burning of the most polluting resource: coal would be used first, followed only later by natural gas. In this literature, renewable energy (modeled as a clean backstop) should never be used early, that is before fossil fuel production stops.

More recently, Amigues et al. (2013) study the extraction of a renewable and a non-renewable energy source, taking into account that the extraction of the renewable source requires to first invest in appropriate capital (renewable power plants) and pay for adjustment costs. They prove that optimal investment in renewable is in this case independent from existing fossil resources; the best strategy is to start to build renewable power early and spread investment over time. ${ }^{2}$ Amigues et al. (2013) let climate policy for further research (the authors do mention that climate policies is an obvious application), consider only one type of fossil fuel, and disregard capacity constraints limiting the extraction of fossil fuels.

On the other hand, there is a nascent literature on the optimal investment in abatement capital (Fischer et al., 2004; Williams, 2010; Vogt-Schilb et al., 2014b). This literature disentangles optimal emission reduction pathways from optimal investment pathways and from carbon prices. In particular, Vogt-Schilb et al. (2014b) study optimal investment in different economic sectors, and find

\footnotetext{
1 This paper assumes gas is a low-carbon substitute for coal. The relative carbon content of gas and coal may actually depend on the type of gas and coal and on the particular processes used for extracting and transporting the fuels (e.g., Alvarez et al., 2012). The relative merits of coal and gas also depend on factors disregarded here, such as impact on energy security or impact on local pollution.

${ }^{2}$ A whole literature started by Kemp and Long (1980) has established that if extraction of an expensive energy source is exogenously constrained, it may be optimal to use that source simultaneously with cheaper alternatives (e.g., Amigues et al., 1998; Holland, 2003). Amigues et al. (2013) confirm this result for endogenous constraints. Other reasons for not extracting resources according to a strict Herfindahl sequence include heterogeneity of both producers and consumers - Gaudet (2014) provides an extensive review.
} 
that the same carbon price translates in more short-term investment in sectors with larger abatement potential and sectors where abatement capital is more expensive. Also, Rozenberg et al. (2014) analyze the trade-off between (i) earlyscrapping existing dirty capital to reduce emissions quickly and (ii) using dirty capital at full capacity to increase short-term production. They find that earlyscraping part of the dirty capital built before climate policies were implemented is optimal for achieving stringent climate targets. ${ }^{3}$ These two last studies are close to our question, but they focus on investment in perfectly clean capital (e.g. renewable power), letting aside any intermediate option (e.g., switching from coal to gas).

This paper attempts to bridge the gap between these two veins of the literature. ${ }^{4}$ We model different types of nonrenewable resources (cheap coal and more expensive gas) and an expensive renewable source, all subject to capacity constraints and adjustment costs (to make irreversible investment in coal, gas, and renewable power plants). We study the optimal transition from existing coal plants to gas and to renewable power under the constraint of a carbon budget.

The analysis brings three findings. First, we confirm and extend the result by Amigues et al. (2013): under capacity constraints and adjustment costs, different energy sources may be used simultaneously. In particular, investment in gas can start before coal is phased out, and most importantly investment in renewable can start before gas or coal are phased out. The reason is that smoothing investment over time reduces adjustment costs. In other words, the availability of appropriate resources (skilled workers, production lines) and the stringency of the carbon budget set an optimal speed at which to deploy renewable power.

We also extend the finding from Rozenberg et al. (2014): it may be optimal to build gas power plants and to decommission them before their natural end of life, even in the absence of a policy shock. Doing so allows for reducing investment in expensive renewable power plants in the short term, moving some efforts to the medium term, when gas power is under-used and replaced by renewable power.

Finally, we extend the result from Vogt-Schilb et al. (2014b), as we find that more investment should go to the expensive zero-carbon renewable power than

\footnotetext{
3 We focus on the analytical literature. Early decommissioning of existing coal power plants has also been studied using numerical models (e.g., Rogelj et al., 2011; IEA, 2014).

4 The interaction of investment and natural resources extraction is also the subject of the theory of the mine (e.g., Campbell, 1980; Gaudet, 1983; Lasserre, 1985), in which installed capital similarly limits the extraction rate of (a single type of) minerals. After reviewing this literature, Cairns (1998) notes that "there can be three phases in the exploitation of the mine, namely (1) a period of positive investment after time $t=0$, in which production is at full capacity, then (2) a period in which investment is zero and production is at full capacity, and finally (3) a period of declining production". This paper is different as we model several resources and a climate constraint, we find however a similar trajectory for exploitation of gas resources.

In addition, Dasgupta and Heal (1974), Solow (1974) and Stiglitz (1974) have started a literature that studies the impact of resource finitude on growth, in green Ramsey models that feature both capital accumulation and resource extraction — van der Ploeg and Withagen (2014) is a recent example. This literature also focuses on a single type of capital and a single fossil resource, while in the present paper we study the transition from coal to gas and renewable power plants.
} 
to the intermediate low-carbon gas power. This is not only because renewable power plants save fossil fuels and carbon taxes, but also because they stay valuable for ever, while gas plants eventually become obsolete.

These results stress the importance of correctly anticipating the effective lifetime of different types of power plants when choosing among them. Such effective lifetime is not only a technical parameter, but also an endogenous choice depending on future investment and production decisions. For instance, the levelized cost of electricity (LCOE), in theory a good metric for comparing investment in different power plants, may be biased against renewable power in practice.

Indeed, different types of power plants are usually compared using the LCOE (e.g. Kost et al., 2012; EIA, 2013; IPCC, 2014), that is the ratio of discounted costs of building and using a power plant, including fuel and GHG emission costs, over the discounted expected electricity production. We find that the LCOE computed against future production, investment and prices should be equal to the average future electricity price. But in practice, fossil fuel, carbon and electricity prices and the resale value of power plants of any given technology may be difficult to anticipate. They depend on future investment and production from all technologies, which depend in turn on future prices and regulations. ${ }^{5}$ We thus investigate whether LCOEs computed against current signals can provide an operational rule of thumb to guide investment decisions. ${ }^{6}$

In a numerical calibration using data from the European electricity sector, we find that such operational LCOE should be several times higher for new renewable power plants than for new gas power plants. Indeed, the operational LCOE does not account for future increases in fuel and carbon prices, and does not consider that gas plants will be under-used in the medium term once replaced by renewable power. As a result, if an agent was to assess investment in new capacity for the European electricity market by computing LCOEs from current prices, she would recommend to invest too much in gas capacity, and not enough in renewable capacity.

The remainder of the paper is structured as follows. Section 1 details the model. Section 2 derives the first-order conditions, optimal production decisions

\footnotetext{
5 One way such investment and production pathways are provided in practice is through numerical models of the electricity sector (e.g., Seebregts et al., 2002; Loulou, 2008) or wider energy-environment-economy models (e.g., Weyant, 2004; Waisman et al., 2012; Kriegler et al., 2014). These models do not always model adjustment costs explicitly, but they take into account the limited ability to switch quickly from high- to low-carbon capital by building on maximum investment speeds (Wilson et al., 2013). Several authors have stressed that in this case optimal investment pathways are in part driven by such exogenous bounds, therefore calling for explicit discussion of their calibration (Wilson et al., 2013; Iyer et al., 2014; VogtSchilb et al., 2014a).

6 Such usage of the LCOE would be consistent with the view, popular in the early literature on investment, that firms can take optimal investment decisions based on current prices and current productivity of capital only (e.g., Arrow, 1964; Jorgenson, 1967, p. 145). It has already been signaled that the efficiency of such myopic investment decisions critically depends on investment prices being exogenous: under endogenous investment costs, optimal investment decisions require to perfectly anticipate all future prices (Gould, 1968; Mussa, 1977). The bad performance of imperfectly computed LCOEs is thus not surprising (and is not a theoretical challenge under the rational expectation hypothesis). The novelty here is in determining the direction and magnitude of the error induced by myopic decision rules in the particular case of the transition to clean electricity.
} 
at each point in time, and the electricity price. It then studies the different phases through which the power sector may go during its transition to renewable power. Section 3 tackles optimal investment decisions and the levelized cost of electricity. Section 4 provides numerical simulations calibrated with data from the European electricity sector. Section 5 concludes.

\section{Model}

A social planner controls the supply of electricity, using and investing in three different technologies: an existing high-carbon technology ( $h$, coal power), a fossil-fueled low-carbon technology ( $\ell$, gas), and an inexhaustible zero-carbon technology ( $z$, renewable power).

At each time $t$, the social planner chooses the physical investment $x_{i, t}$ in technology $i$. The investment adds to the installed capacity $k_{i, t}$, which depreciates at the constant rate $\delta$ (dotted variables denote temporal derivatives): ${ }^{7}$

$$
\forall i, \quad \dot{k}_{i, t}=x_{i, t}-\delta k_{i, t}
$$

Physical investment is made at a positive, increasing and convex cost $c_{i}\left(x_{i, t}\right)$ :

$$
c_{i}>0, c_{i}^{\prime}>0, c_{i}^{\prime \prime}>0
$$

This captures the increasing opportunity cost to use scarce resources (skilled workers and appropriate capital) in order to build and deploy capacities faster. We assume that low-carbon capacity is cheaper than zero-carbon capacity in the sense that:

$$
\forall x \quad c_{\ell}^{\prime}(x)<c_{z}^{\prime}(x)
$$

Without loss of generality, we assume low-carbon and zero-carbon capacities to be nil at the beginning $\left(k_{\ell, t_{0}}=k_{z, t_{0}}=0\right) .^{8}$

The social planner then chooses how much output to produce from each technology. We assume production exhibits constant returns to scale: two gas plants can produce twice as much electricity as one gas plant. ${ }^{9}$ The positive production $q_{i, t}$ with technology $i$ cannot exceed the installed capacity $k_{i, t}$ :

$$
\begin{aligned}
\forall i, \quad 0 \leq q_{i, t} \\
\\
q_{i, t} \leq k_{i, t}
\end{aligned}
$$

\footnotetext{
7 Through this paper, capacity is to be understood as equivalent capacity, e.g., in $\mathrm{kWh} / \mathrm{yr}$, unless otherwise specified. For instance if $2 \mathrm{~kW}$ of windmills are required to provide as much output per year as $1 \mathrm{~kW}$ of coal, then $2 \mathrm{~kW}$ of windmills are accounted as $1 \mathrm{~kW} e q$.

8 The reason why this assumption does not result in a loss of generality is that our model studies the transition from the existing situation to cleaner and to clean power.

${ }^{9}$ We thus neglect the imperfect substitution between gas and renewable plants that comes from their respective cost structures (in terms of fixed versus variable costs), for instance making gas more suitable for peak power than coal. We are thus implicitly assuming that such considerations have more impact on the optimal electricity mix at the equilibrium than on the transition from the existing state to that equilibrium, which is the focus of the paper (see also Vogt-Schilb et al., 2014b).
} 
For simplicity, we assume the existing carbon-intensive capital is overabundant, such that (4) is not binding for coal; this assumption is relaxed and confirmed in the numerical application. ${ }^{10}$

Let $F_{i}$ be the carbon intensity (or emission factor) of technology $i$. The highcarbon technology is more carbon-intensive than the low-carbon technology:

$$
F_{h}>F_{\ell}>F_{z}=0
$$

The social planner is subject to an exogenous carbon budget (or emission ceiling), cumulative emissions cannot exceed a given ceiling $\bar{M}$ :

$$
\forall t, \quad m_{t} \leq \bar{M}
$$

Where cumulative emissions $m_{t}$ grow with emissions $F_{i} q_{i, t}$ :

$$
\dot{m}_{t}=\sum_{i} F_{i} q_{i, t}
$$

Cumulative emissions have been found to be a good proxy for global warming (Allen et al., 2009; Matthews et al., 2009). Some policy instruments, such as an emission trading scheme with unlimited banking and borrowing, set a similar constraint on firms (Slechten, 2013).

Using fossil fuel (gas or coal) requires to extract exhaustible resource from an initial stock, such that the current stock $S_{i, t}$ classically satisfies:

$$
\begin{aligned}
& S_{i, t_{0}} \text { given } \\
& \dot{S}_{i, t}=-q_{i, t} \\
& S_{i, t} \geq 0
\end{aligned}
$$

While it is convenient to use the above general notations (indexed by $i$ ), we will follow van der Ploeg and Withagen (2012) and focus on the case where the zero carbon technology is renewable and coal is overabundant $\left(S_{z, t_{0}}=S_{h, t_{0}}=\infty\right)$. This is equivalent to recognize the carbon budget is more stringent than the scarcity of coal resources - as it will be discussed later, this assumption is likely to hold for gas resources as well, especially with the recent developments of non-conventional extraction methods.

Consumers derive utility $u\left(\sum_{i} q_{i, t}\right)$ from electricity consumption, where $u$ satisfies the Inada conditions and is smooth enough. The program of the social planner consists in determining the trajectories of investment $x_{i, t}$ and production $q_{i, t}$ that maximize discounted utility net from investment costs while complying with the carbon budget $\bar{M}$ and the various constraints:

$$
\begin{aligned}
& \max _{x_{i, t}, q_{i, t}} \int_{0}^{\infty} e^{-r t}\left[u\left(\sum_{i} q_{i, t}\right)-\sum_{i} c_{i}\left(x_{i, t}\right)\right] d t \\
& \text { s.t. } \dot{k}_{i, t}=x_{i, t}-\delta k_{i, t} \quad\left(\nu_{i, t}\right) \\
& q_{i, t} \leq k_{i, t} \quad\left(\gamma_{i, t}\right) \\
& q_{i, t} \geq 0 \quad\left(\lambda_{i, t}\right)
\end{aligned}
$$

\footnotetext{
10 Rozenberg et al. (2014) offer a proof that carbon-intensive capital becomes overabundant at the moment when a carbon price is implemented.
} 


$$
\begin{aligned}
& \dot{m}_{t}=\sum_{i} F_{i} q_{i, t} \quad\left(\mu_{t}\right) \\
& m_{t} \leq \bar{M} \quad\left(\eta_{t}\right) \\
& \dot{S}_{i, t}=-q_{i, t} \quad\left(\alpha_{i, t}\right) \\
& S_{i, t} \geq 0 \quad\left(\beta_{i, t}\right)
\end{aligned}
$$

Where $r$ is the constant discount rate and the Greek letters in parentheses are the costate variables and Lagrange multipliers (all chosen such that they are positive): among them, $\nu_{i, t}$ is the shadow cost of new power plants; $\gamma_{i, t}$, the social cost of the capacity constraint, can also be interpreted as the shadow rental cost of capital or the marginal productivity of capital; $\mu_{t}$ is the shadow carbon price; and $\alpha_{i, t}$ the shadow price of resource $i$ (all notations are gathered in Table A.5).

\section{Sequencing production from and investment in competing tech- nologies}

\subsection{Optimal production decisions}

We start the resolution with the first order conditions, which translate the equilibrium between production decisions and electricity prices at each point in time. Indeed, during a time interval $\left(\tau_{i}^{+}, \tau_{i}^{-}\right)$when production and investment with technology $i$ are strictly positive, the first-order conditions simplify to the following (see Appendix A for the complete set of equations):

$$
\forall t \in\left(\tau_{i}^{+}, \tau_{i}^{-}\right), \quad(\delta+r) c_{i}^{\prime}\left(x_{i, t}\right)-\frac{d}{d t} c_{i}^{\prime}\left(x_{i, t}\right)=u_{t}^{\prime}-\alpha_{i, t}-\mu_{t} F_{i}
$$

On the right hand side of (10), $u_{t}^{\prime}$ is the competitive electricity price $\left(u_{t}^{\prime}\right.$ stands for $\left.u^{\prime}\left(\sum_{i} q_{i, t}\right)\right), \alpha_{i, t}$ is the fuel cost, $F_{i}$ the carbon intensity of fuel $i$, and $\mu_{t}$ is the carbon price.

The left hand side is what Vogt-Schilb et al. (2014b) call the marginal implicit rental cost of capital (MIRCC), extending the concept of implicit rental cost of capital proposed by Jorgenson (1967) to the case of endogenous capacity prices. It is the rental price that ensures agents are indifferent between buying and renting capacity. More specifically, the relation means there is no profitable tradeoff between the two following strategies: (i) buy capital at $t$ at a $\operatorname{cost} c_{i}^{\prime}\left(x_{i, t}\right)$, rent it out during one period $d t$ at the rental price, then sell the depreciated $(\delta)$ capacities at $t+d t$ at a price $c_{i}^{\prime}\left(x_{i, t}\right)+\frac{d}{d t} c_{i}^{\prime}\left(x_{i, t}\right) d t$ or (ii) simply lend money at the interest rate $r$.

Equation (10) can thus be seen as an application of the equimarginal principle: it provides a simple rule to arbitrate production decisions at each moment. It shows that at each time step, production decisions may be taken relying only on current prices - the rental price of capacities and the price of electricity.

\subsection{Electricity price and types of phases}

Equation (10) can also be used to determine the price of electricity, depending on which one is the (short-term) marginal power plant:

Lemma 1. The output price $u_{t}^{\prime}$ is given by the variable costs of the marginal technology, which includes a strictly positive rental cost only if capacities are fully used. Three types of situations are possible: 
1. When coal capacities are used at less than full capacity, electricity price is given by variable costs from coal generation:

$$
0<q_{h, t}<k_{h, t} \Longrightarrow u_{t}^{\prime}=\alpha_{h, t}+F_{h} \mu_{t}
$$

2. When gas capacities are used at less than full capacity, electricity price is given by variable costs from gas generation:

$$
0<q_{\ell, t}<k_{\ell, t} \Longrightarrow u_{t}^{\prime}=\alpha_{\ell, t}+F_{\ell} \mu_{t}
$$

3. If all capacities are either used at full or not used at all, rental costs adjusts such that electricity price is set by the implicit rental cost of renewable capacity:

$$
\begin{aligned}
\forall i, q_{i, t} \in\left\{k_{i, t}, 0\right\} \Longrightarrow u_{t}^{\prime} & =\alpha_{i, t}+F_{i} \mu_{t}+(\delta+r) c_{i}^{\prime}\left(x_{i, t}\right)-\frac{d}{d t} c_{i}^{\prime}\left(x_{i, t}\right) \\
& =(\delta+r) c_{z}^{\prime}\left(x_{z, t}\right)-\frac{d}{d t} c_{z}^{\prime}\left(x_{z, t}\right)
\end{aligned}
$$

In particular, it is not possible that at a given date gas and coal are both used at less than full capacity ${ }^{11}$ and renewable power is never used at less than full capacity.

Proof. The results are straightforward once it is noted that $\gamma_{i, t}$, the Lagrange multiplier associated with the capacity constraint, is zero when capacity $i$ is underused, and that $\gamma_{i, t}$ equals the implicit rental cost of capital (Appendix A).

Lemma 1 thus defines implicitly three types of phases through which electricity production may go during the transition from coal-fired to renewable power - and implies that the price may jump when the system changes phases and capacity constraint start or stop being binding (Wang and Zhao, 2013, offer a discussion of price jumps).

As discussed in the next subsection, the ordering of these three types of phases may vary. Fig. 1 illustrates one particular situation where investment in both renewable and gas power start at the beginning of the period - a sufficient condition is that $c_{i}^{\prime}(0)=0$. In a first phase, coal is progressively replaced by renewable and gas, coal capacity is underused and electricity price is given by the variable cost of coal. When coal is phased out follow two phases during which renewable power progressively replaces gas. First gas is used at full capacity, and electricity price depends on the marginal implicit rental cost of renewable capacities. At one point meeting the emission constraint requires gas production to decrease faster than its capacity depreciates: gas plants are underused and the price is set by variable costs from gas. During the final phase, all production comes from renewable power.

\footnotetext{
${ }^{11}$ We disregard the case where fuel costs compensate exactly differences in carbon intensities $\alpha_{\ell}-\alpha_{h}=\mu\left(F_{h}-F_{\ell}\right)$ as it requires a very restrictive set of assumptions.
} 


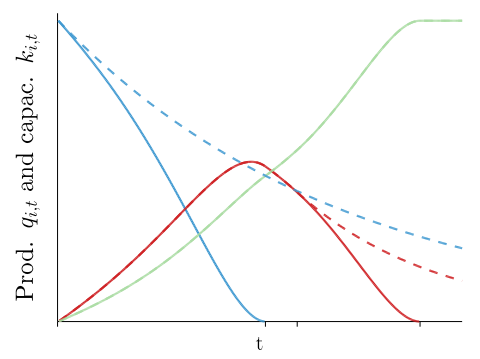

(a) Production and capacity

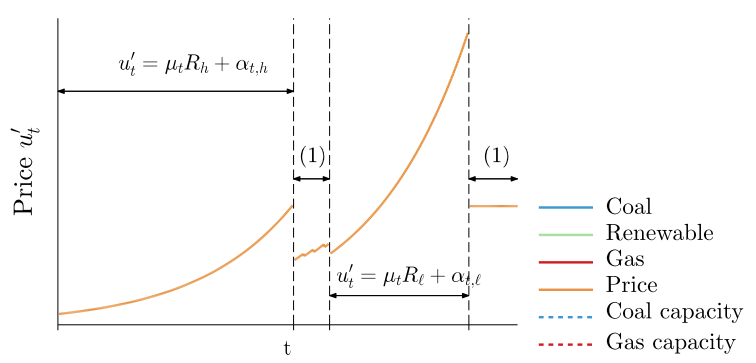

(b) Output price

Figure 1:

Output price during the three types of phases.

(1): $u_{t}^{\prime}=(\delta+r) c_{z}^{\prime}\left(x_{z, t}\right)-\frac{d}{d t} c_{z}^{\prime}\left(x_{z, t}\right)$

\subsection{Ordering investment in low- and zero-carbon capacity}

In this subsection we study the various phases through which the system may go during the transition from coal to renewable. Three particular dates play a pivotal role.

To comply with the carbon budget constraint, all production must eventually switch to renewable power, at a first date that we denote $T$ (Fig. 2). At one point, polluting coal production is thus completely phased out, at a second date $T_{h}^{-} \leq T$. Similarly, while gas plants may be used during the transition, at one point gas production has to decline, possibly faster than the speed at which its capacity depreciates. This may result in an underutilization of gas capacity, at a third date $T_{\gamma}$.

In Appendix B, we systematically list the various possible transition shapes, and identify three possible sequences of investment in gas and renewable power:

Proposition 1. Depending on the parameters, investment phases may be ordered in three ways:

1. Two successive transitions. Gas first completely replaces coal, then renewable power replaces gas. In this case, investment in renewable power starts after coal is phased out, but before production from gas is phased out (Fig. 2a).

2. Gas and wind simultaneously replace coal. In this case, investment in renewable starts before production from any fossil resources is phased-out (Fig. 2b).

3. Starting with investment in renewable power. In this case, investment in renewable power starts before investment in gas power (Fig. 2c).

Proof. See Appendix B.

\section{Assessing investment in competing technologies}

In this section, we study optimal investment decisions. We first derive a general investment decision rule, showing that all future prices and the future 

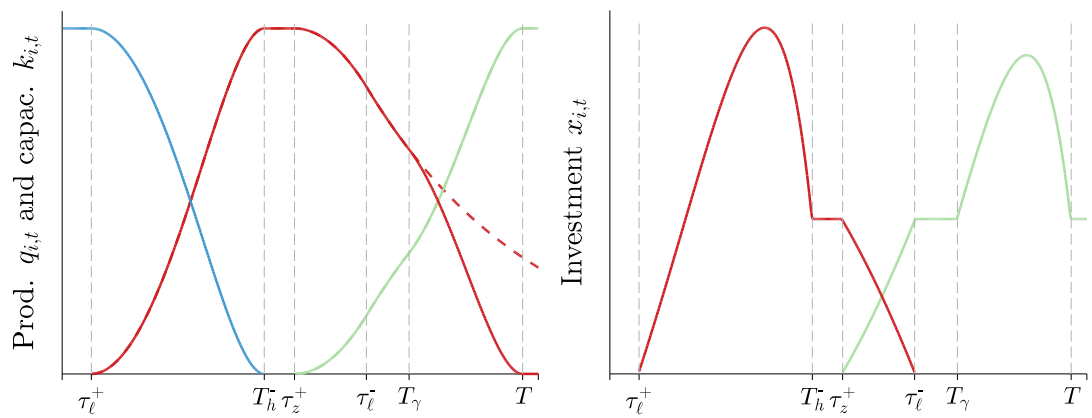

(a) Two successive transitions
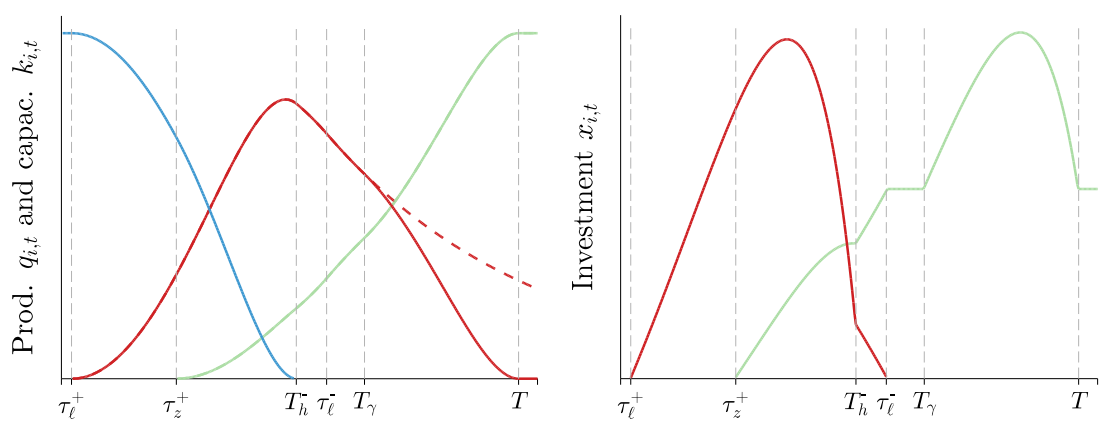

(b) Gas and wind simultaneously replace coal
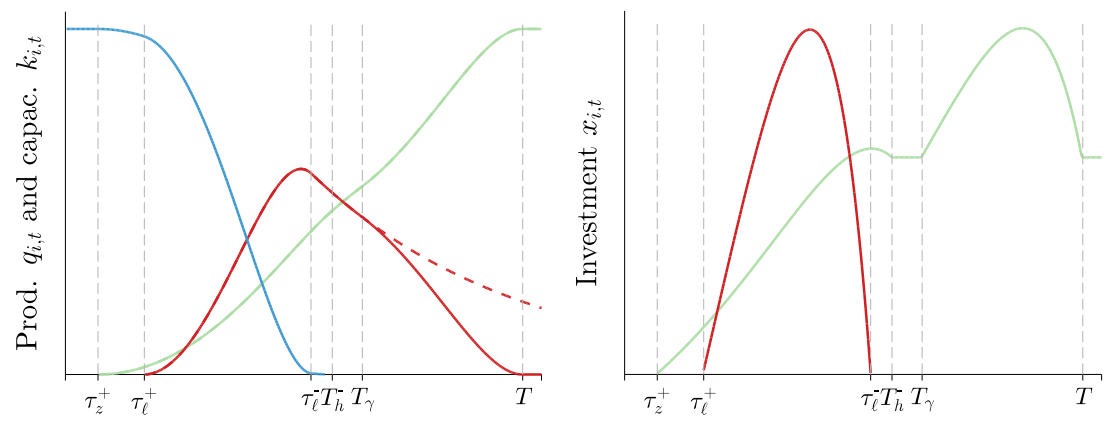

(c) Starting with investment in renewable power

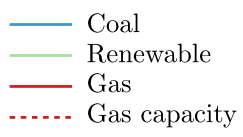

Figure 2: Numerical simulations of three possible transition profiles. Figures on the left display production and capacity, figures on the right display optimal investment. The parameters used to produce these figures are gathered in Table B.6. 
resale value of capital are required to determine the optimal investment strategy. We then discuss the levelized cost of electricity and investigate consequences of failing to anticipate all future prices.

\subsection{General investment decision equation}

During a time interval $\left(\tau_{i}^{+}, \tau_{i}^{-}\right)$when production and investment are strictly positive, the optimal marginal investment cost $c_{i}^{\prime}\left(x_{i, t}\right)$ is the solution of the differential equation (10). In general, such solution reads: ${ }^{12}$

$$
\begin{aligned}
& \forall t \in\left(\tau_{i}^{+}, \tau_{i}^{-}\right), \\
& \quad c_{i}^{\prime}\left(x_{i, t}\right)=\int_{t}^{\tau_{i}^{-}} e^{-(r+\delta)(\theta-t)}\left(u_{\theta}^{\prime}-\mu_{\theta} F_{i}-\alpha_{i, \theta}\right) d \theta+e^{-(r+\delta)\left(\tau_{i}^{-}-t\right)} c_{i}^{\prime}\left(x_{i, \tau_{i}^{-}}\right)
\end{aligned}
$$

The right hand side decomposes in two terms: (i) the present value of all future revenues from selling the output minus costs from emission and resource usage $\left(u_{t}^{\prime}-\mu_{t} F_{i}-\alpha_{i, t}\right)$ produced by the depreciated marginal unit of capacity $\left(e^{-(r+\delta)(t-\theta)}\right)$, plus (ii) the contribution of the marginal investment to the capacity installed at $\tau_{i}^{-}$, valued at its replacement cost or resale value $c_{i}^{\prime}\left(x_{i, \tau_{i}^{-}}\right)$.

Again, the optimal investment trajectory is given by a marginalist argument: the capacity cost is equal to all the future discounted net revenues, including a resale value. Equation (15) means that the optimal investment cost in one technology can be superior or inferior to the other, depending in particular on the dates when it is optimal to invest and use each technology $\left(\tau_{i}^{+}, \tau_{i}^{-}\right)$.

\subsection{The intertemporal merits of investment in gas and renewable power}

Proposition 1 means that it may be optimal to invest in both renewable and gas power at the same time. Equation (15) implies that in this case, more investment should go to renewable power.

Indeed, producing electricity from renewable power does not require to buy fossil fuel or pay for the carbon price. Moreover, renewable power plants keep a residual value forever (as during the final phase, all investment goes to maintain renewable power at its maximum capacity), while investment in gas power eventually stops, leaving gas plants with a lower residual value:

Corollary 1. On the optimal pathway, when the social planner invests in both the zero- and the low-carbon technology, it builds zero-carbon capacity at a higher marginal investment cost than low-carbon capacity.

Proof. From (15), now denoting $\tau_{i}^{+}$the date when investment in capacity $i$ optimally starts and $\tau_{\ell}^{-}$the date when investment in gas optimally stops:

$$
\begin{aligned}
& \forall t \in\left[\max _{i}\left(\tau_{i}^{+}\right), \tau_{\ell}^{-}\right], \quad c_{z}^{\prime}\left(x_{z, t}\right)-c_{\ell}^{\prime}\left(x_{\ell, t}\right)= \\
& \underbrace{\int_{t}^{\tau_{\ell}^{-}} e^{-(r+\delta)(\theta-t)}\left(\mu_{\theta} F_{\ell}+\alpha_{\ell, \theta}\right) d \theta}_{\Delta p}+\underbrace{\left(c_{z}^{\prime}\left(x_{z, \tau_{\ell}^{-}}\right)-c_{\ell}^{\prime}(0)\right) e^{(r+\delta)\left(t-\tau_{\ell}^{-}\right)}}_{\Delta c^{\prime}}
\end{aligned}
$$

$\Delta p$ is the discounted value of emissions and fossil fuels that the marginal renewable capacity built at time $t$ allows saving before $\tau_{\ell}^{-}$when compared to the

12 Equation 15 is the textbook solution of equation 10 (e.g., Wikibooks contributors, 2014) 
marginal gas capacity built at time $t$.

$\Delta c^{\prime}$ is the difference between the discounted values of the marginal capacities built at $t$ which will depreciate from $\mathrm{t}$ to $\tau_{\ell}^{-}$. It is strictly positive, as $c_{z}^{\prime}\left(x_{z, \tau_{\ell}}\right)>c_{z}^{\prime}(0)$ by assumption $(2)$ and $c_{z}^{\prime}(0)>c_{\ell}^{\prime}(0)$ by assumption (3). 


\subsection{Levelized cost of electricity (LCOE)}

Here we investigate whether the Levelized cost of electricity (LCOE) can be used as an operational rule of thumb to value different power plants. Let us consider an incremental unit of capacity built during an interval when investment is positive (at $t \in\left(\tau_{i}^{+}, \tau_{i}^{-}\right)$). Dividing its optimal investment costs (15) with its discounted production over the same time interval yields:

$$
\begin{array}{r}
\forall t \in\left(\tau_{i}^{+}, \tau_{i}^{-}\right), \quad \frac{\int_{t}^{\tau_{i}^{-}} e^{-(r+\delta)(\theta-t)} u_{\theta}^{\prime} d \theta}{\int_{t}^{\tau_{i}^{-}} e^{-(\delta+r)(\theta-t)} d \theta}=\frac{\int_{t}^{\tau_{i}^{-}} e^{-(r+\delta)(\theta-t)}\left(\mu_{\theta} F_{i}+\alpha_{i, \theta}\right) d \theta}{\int_{t}^{\tau_{i}^{-}} e^{-(\delta+r)(\theta-t)} d \theta} \\
+\frac{c_{i}^{\prime}\left(x_{i, t}\right)-e^{-(r+\delta)\left(\tau_{i}^{-}-t\right)} c_{i}^{\prime}\left(x_{i, \tau_{i}^{-}}\right)}{\int_{t}^{\tau_{i}^{-}} e^{-(\delta+r)(\theta-t)} d \theta}
\end{array}
$$

Equation (17) defines the levelized cost of electricity (LCOE) produced with technology $i$. The first term in the right hand side is the discounted variable cost (from carbon and resource prices) over the discounted production; the second term corresponds to the investment costs of the marginal unit of capacity at $t$ minus its residual value at $\tau_{i}^{-}$, over the discounted future production (the levelized cost of the capacity net of its residual value). The left-hand side is the average output price weighted by discounted production during $\left(t, \tau_{i}^{-}\right)$.

Equation (17) states that at the optimum, the LCOE is equal to the weighted average future price of the output. The relevant weight is the discounted production from the deprecating capacity. In other terms, electricity priced at the optimal LCOE covers for the complete cost of building and operating a power plant. ${ }^{13}$ In practice, using this relationship to assess investment requires to know in advance the future prices of additional capacity, resources, emissions and output. This may be challenging for actual agents willing to schedule or monitor investment in different types of power plants. For instance, it is recognized that governments have in general little capacity to commit, and in particular to commit to specific future carbon price levels (Helm et al., 2003; Golombek et al., 2010; Ulph and Ulph, 2013). ${ }^{14}$

The question we address here is whether LCOEs computed against current price signals may provide an operational rule of thumb to value different types of power plants. ${ }^{15}$ Such an operational LCOE reads:

$$
\mathcal{L}_{i, t}=(r+\delta) c_{i}^{\prime}\left(x_{i, t}\right)+\mu_{t} F_{i}+\alpha_{i, t}
$$

$\mathcal{L}_{i, t}$ is the sum of the annualized investment cost, the carbon cost and the fuel cost.

Proposition 2. Equalizing the operational LCOE across technologies would lead to invest relatively too much in gas power and too little in renewable power

\footnotetext{
13 We ignore here all intermittency issues, which add a cost to renewable sources, and may be a rationale to use some gas during the final phase (Joskow, 2011; Ambec and Crampes, 2012; Bazilian et al., 2013; Ueckerdt et al., 2013).

14 See also Spiro (2012) on the limited capacity of investors and regulators to anticipate prices over long time horizons.

${ }^{15}$ As discussed in footnote 6, such operational LCOE is consistent with the idea that agents can take optimal investment decisions based on current price signals only.
} 
Proof. Let $\tilde{x}_{z, t}$ and $\tilde{x}_{\ell, t}$ be two investment schedules that equalize the operational LCOE accross technologies, such that:

$$
\begin{aligned}
(r+\delta) c_{z}^{\prime}\left(\tilde{x}_{z, t}\right)+\mu F_{z}+\alpha_{z} & =(r+\delta) c_{\ell}^{\prime}\left(\tilde{x}_{\ell, t}\right)+\mu F_{\ell}+\alpha_{\ell} \\
\Longrightarrow c_{z}^{\prime}\left(\tilde{x}_{z, t}\right)-c_{\ell}^{\prime}\left(\tilde{x}_{\ell, t}\right) & =\frac{\mu F_{\ell}+\alpha_{\ell}}{r+\delta}
\end{aligned}
$$

Comparing the allocation implied by (20) with the optimal rule stated in Corollary 1 shows that equalizing the operational LCOE across technologies misses the future increase for carbon and fossil resources prices, and misses the term correcting for future changes in the value of capacities, leading to relatively too much investment in gas power and not enough investment in renewable power.

In the next section we use numerical simulations calibrated on the European power sector and find that during the optimal transition to clean power, renewable power plants should be built at an operational LCOE several times higher than new gas power plants.

\section{Numerical application to the European electricity sector}

\subsection{Functional forms, data and calibration}

We calibrate the model with data from the European power sector as described in the European 2050 Energy Roadmap (EU, 2011). In this numerical application, efficient gas power plants (the low-carbon technology) and onshore wind (the zero-carbon technology) are used to phase out the existing polluting capacities represented as the average legacy thermal production mix (Table 1).

To better fit the data, we express installed capacity $k_{i, t}$ in peak capacity (GW), and production $q_{i, t}$ in GWh/yr. Production is constrained by a maximum number of operating hours $H_{i}$. For instance, a given windmill will produce electricity only at the moments where it is windy, which expectedly happens a given number of hours per year.

We assume for simplicity that all technologies have the same depreciation rate $\delta$, calibrated as $\delta=1$ /lifetime assuming a lifetime of 30 years (IEA, 2010). We consider that Europe is price-taker on the fossil resources costs $\alpha_{i, t}$, which follows the trajectory assumed in the European 2050 Roadmap (Table 2). Note that $\alpha_{h}$ corresponds to the average price of the resources of the legacy technology $\operatorname{mix}$ (Table 1).

To calibrate the cost functions, we assume that when investment equals the actual average annual investment flow in Europe between 2009 and $2011\left(X_{i}\right)$, the marginal investment $\operatorname{cost} C_{i}^{m}$ is equal to the OECD median value for 2010 (as found in IEA, 2010). We write the cost function as:

$$
\begin{gathered}
c_{i}\left(x_{i, t}\right)=C_{i}^{m} \cdot X_{i} \cdot\left(A \frac{x_{i, t}}{X_{i}}+\frac{1-A}{2}\left(\frac{x_{i, t}}{X_{i}}\right)^{2}\right) \\
\Longrightarrow c_{i}^{\prime}\left(X_{i}\right)=C_{i}^{m}
\end{gathered}
$$

$A \in(0,1)$ is a convexity parameter, equal across technologies for simplicity. When $A=1$, the marginal investment cost are constant, there is no adjustment cost for production capacity, and optimal investment pathways can exhibit jumps. When $A=0$, the marginal cost curves are linear, capacity accumulated at very low speed is free $\left(\lim _{x_{i, t} \rightarrow 0 ; A=0} c_{i}^{\prime}\left(x_{i, t}\right)=0\right)$, and the cost of new 
Table 1: Technology sets considered in the numerical model

\begin{tabular}{lcl}
\hline Set & Abbreviation & \multicolumn{1}{c}{ Composition } \\
\hline & & Average thermal production mix in \\
High carbon technology & Legacy & 2008: 40\% gas, 50\% coal, 10\% oil (EN- \\
& & ERDATA, 2012) \\
Low carbon technology & Gas & Efficient gas \\
Zero carbon technology & Wind & Onshore wind \\
\hline
\end{tabular}

Table 2: Fuel price trajectories of the fossil technology sets in $\$ / \mathrm{MWh}$ (EU, 2011)

\begin{tabular}{lcccc}
\hline & 2008 & 2025 & 2035 & 2050 \\
\hline Legacy & 42.5 & 46 & 48 & 39 \\
Gas & 65 & 76 & 75 & 60 \\
\hline
\end{tabular}

capacity doubles when the investment pace doubles. For intermediate value $A \in(0,1)$, new capacity is always costly, and the marginal cost of new capacity increases with the investment pace. We first assume quadratic costs (that is linear marginal costs and $A=0$ ), and perform later a sensitivity anaysis on $A$.

The demand is assumed inelastic in the short-term, and follows an exogenous long-term growth. Its value in 2008 is calibrated as the reference fossil energy production (from coal, oil and gas), that is $D_{0}=1940 \mathrm{TWh} / \mathrm{yr}$ (ENERDATA, 2012). The central scenario of the Roadmap forecasts a $700 \mathrm{TWh} / \mathrm{yr}$ increase of electricity consumption between 2008 and 2050, that we model as a linear growth of $G=16.5 \mathrm{TWh} / \mathrm{yr}^{2}$. Demand after time $t$ is thus:

$$
D_{t}=D_{0}+t \cdot G
$$

Acording to Trotignon and Delbosc (2008), emission allowances allocated to the power sector in 2008 amounted to $E_{\text {ref }}=1.03 \mathrm{GtCO}_{2} / \mathrm{yr}$, leading to a reference emission rate of $530 \mathrm{tCO}_{2} / \mathrm{GWh}$. A linear decrease of these emissions until 2050, as planned in the Roadmap, yields a carbon budget of $\bar{M}=22 \mathrm{GtCO}_{2}$. A sensitivity analysis on $\bar{M}$ is performed later. We use $r=5 \% /$ yr for the social discount rate.

\subsection{Results}

Fig. 3 shows production, investment, the investment cost, the electricity price and the operational LCOE obtained in the numerical application. The following lists several interesting results.

The social planner does not invest in the legacy capacity; moreover, existing legacy plants start being decommissioned as soon as the climate policy is implemented (Fig. 3a). In the central scenario, legacy fossil-fueled plants are entirely phased out in 2028. With our technology assumptions, the carbon budget is too loose to justify a complete transition by 2050 , but instead phases out all fossil production by 2064 . 
Table 3: Technology-specific data used in the numerical application

\begin{tabular}{|c|c|c|c|c|c|c|}
\hline & Description & Unit & Legacy & Gas & Wind & Source \\
\hline$C_{i}^{m}$ & $\begin{array}{l}\text { Nominal } \\
\text { investment costs }\end{array}$ & $\$ / \mathrm{kW}$ & 1800 & 1200 & 2000 & IEA (2010) \\
\hline$X_{i}$ & $\begin{array}{l}\text { Average annual } \\
\text { new capacity in } \\
\text { Europe }\end{array}$ & $\mathrm{GW} / \mathrm{yr}$ & 4.2 & 11 & 10 & ENERDATA (2012) \\
\hline$H_{i}$ & $\begin{array}{l}\text { Average annual } \\
\text { operating hours }\end{array}$ & $\mathrm{h} / \mathrm{yr}$ & 7500 & 7500 & 2000 & IEA (2010) \\
\hline$F_{i}$ & Carbon intensity & $\mathrm{gCO}_{2} / \mathrm{kWh}$ & 530 & 330 & 0 & $\begin{array}{l}\text { ENERDATA (2012); } \\
\text { Trotignon and Delbosc } \\
(2008)\end{array}$ \\
\hline
\end{tabular}

Table 4: General parameter values used in the numerical application

\begin{tabular}{llccc}
\hline & \multicolumn{1}{c}{ Description } & Unit & Value & Source \\
\hline$r$ & Discount rate & $\% / \mathrm{yr}$ & 5 & \\
$\bar{M}$ & Carbon budget (central value) & $\mathrm{GtCO}_{2}$ & 22 & $\mathrm{UE} \mathrm{(2011)}$ \\
$D_{0}$ & Electricity demand in 2008 & $\mathrm{TWh} / \mathrm{y}$ & 1940 & ENERDATA (2012); \\
$G$ & Annual growth of demand & $\mathrm{TWh} / \mathrm{y}$ & 16.5 & $\mathrm{EU}(2011)$ \\
$\delta$ & Depreciation rate & $\% / \mathrm{yr}$ & 3.33 & $\mathrm{IEA}(2011)$ \\
$A$ & Convexity parameter (central value) & $\cdot$ & 0 & \\
\hline
\end{tabular}

Investment in renewable starts at the beginning of the transition, at the same time as gas and before coal or gas are phased out (Fig. 3c). It grows over time, and only decreases for a short period from 2055 to 2064 when gas is phased out, as most of the power plants have already been replaced (Fig. 3a). Investment in renewable starts at $22 \mathrm{GW} / \mathrm{yr}$ in 2008 , more than twice the actual average investment rate observed between 2009 and 2011, and reaches $70 \mathrm{GW} / \mathrm{yr}$ in 2060. Investment grows again after 2064 to maintain the installed renewable capacity and meet the growing demand.

Gas plants operate as a temporary bridge between coal and renewable. As seen in Fig. 3c, investment in gas starts since the beginning of the transition in 2008, lowering the need for investment in renewable. In 2035, however, investment in gas stops and gas capacities start being underused, allowing gas to be replaced faster by renewable power. The sensitivity analysis (Fig. 4d) shows that it is optimal to build gas power plants transiently for any positive carbon budget ranging up to $45 \mathrm{GtCO}_{2}$ : investment always starts in 2008 and, with quadratic investment costs, plants are underused immediately after investment stops. Only carbon budgets lower than $17 \mathrm{GtCO}_{2}$ make gas investment stop before 2020 (for comparison, the Roadmap implicitly sets a budget of $22 \mathrm{GtCO}_{2}$ ).

Fig. 4c shows that the optimal maximal gas capacity increases with the convexity of the investment functions (when $A$ tends to 0 ). The more convex the investment costs, the more renewable investment must be smoothed and the 


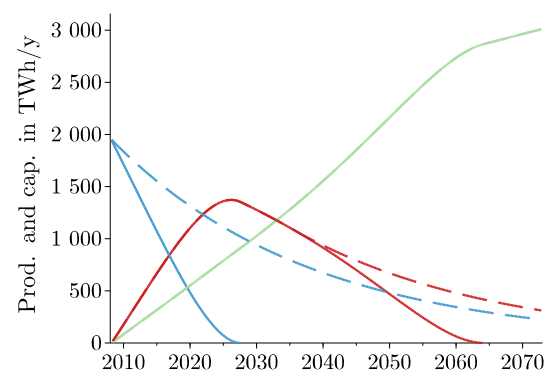

(a) Production and capacity

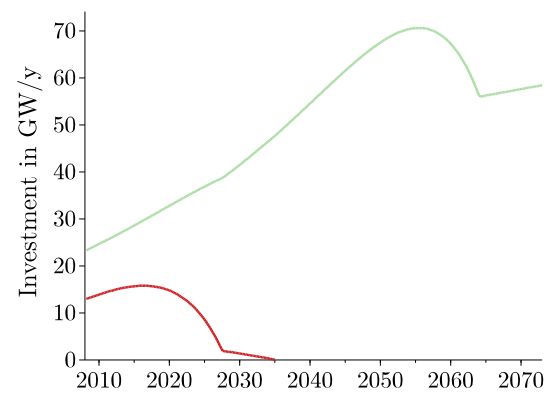

(c) Investment

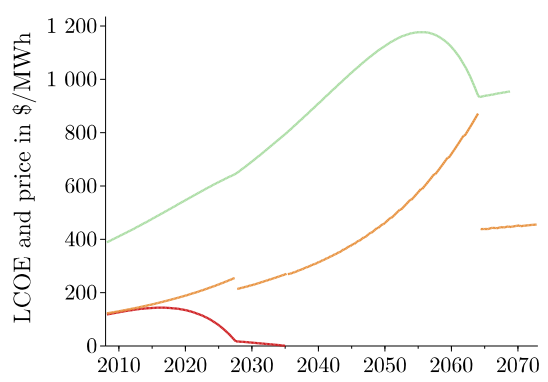

(b) Operational levelized cost of electricity and electricity price

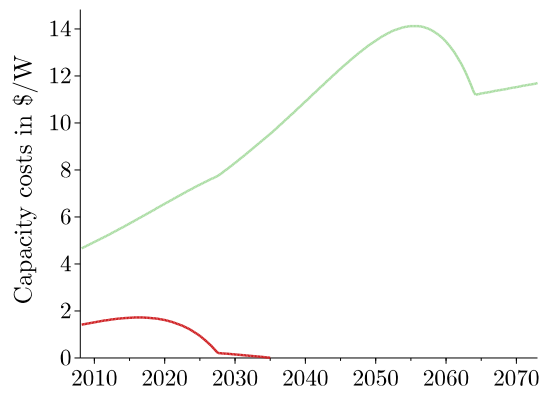

(d) Marginal investment cost

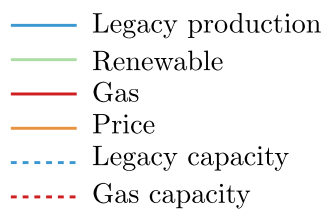

Figure 3: Numerical application to the European electricity sector

more gas is needed. In contrast, for constant investment costs (when $A$ tends to 1 ), the social planner would replace all the stock of capital with renewable power plants at once.

The capacity cost is always higher for renewable than for gas - as predicted by Corollary 1. Fig. 3d displays the marginal costs for new capacities (gas and renewable) along the period. They essentially follow the investment trajectories. Gas investment costs decrease from 2015 on, as the average power plants becomes less and less carbon-intensive, making investment in low carbon capacity less and less profitable.

Electricity prices are displayed in Fig. 3b. In a first phase, before 2028, the marginal capacity is the legacy dirty technology. The endogenous carbon price is $137 \$ / \mathrm{tCO}_{2}$, representing $73 \$ / \mathrm{MWh}$ or $63 \%$ of the electricity price during the phase while the legacy power plant is marginal. After the dirty technology has been phased out, gas becomes the marginal technology and is under-used from 2036 to 2064 . In between and after fossil technologies have been phased out, the electricity price equals the rental cost of renewable power plants (Lemma 1).

Finally, along the simulated optimal path, the levelized cost of electricity 


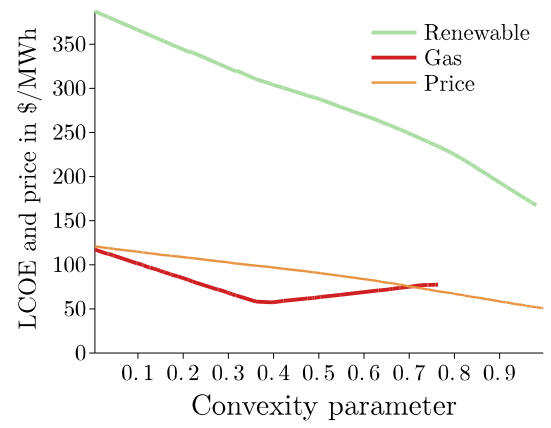

(a) LCOE and price in 2008 as a function of the convexity parameter $A$

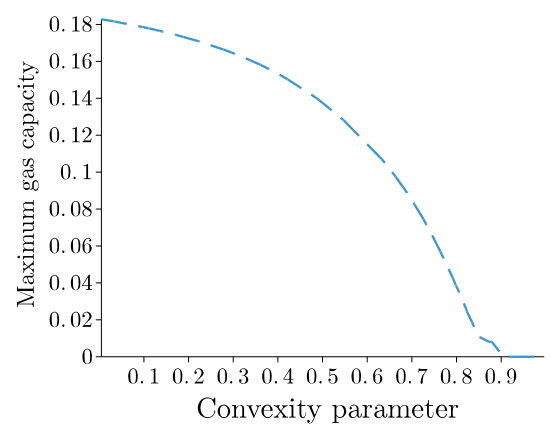

(c) Maximal gas capacity as a function of the convexity parameter $A$

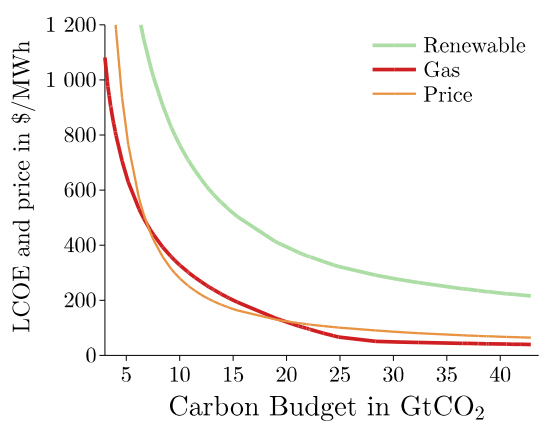

(b) LCOE and price in 2008 as a function of the carbon budget $\bar{M}$

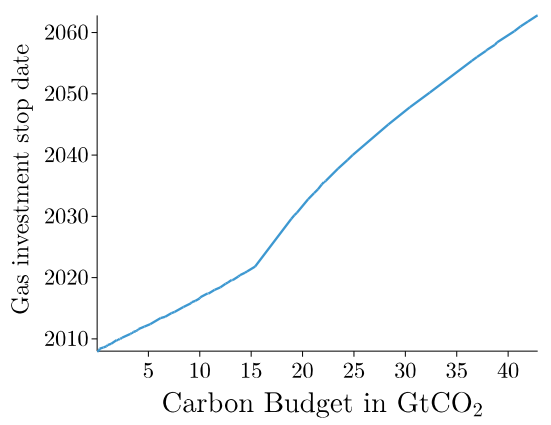

(d) Date when gas investment stops as a function of the carbon budget $\bar{M}$

Figure 4: Sensitivity analysis on the carbon budget and the convexity parameter

computed against current prices and current returns (the operational LCOEs) is several times higher for renewable power than for gas. Fig. 3b shows the LCOEs and the electricity price. The LCOE is higher than the electricity price for renewable plants, and lower for gas plants. Fig. $4 \mathrm{a}$ and $4 \mathrm{~b}$ show the operational LCOEs of renewable and gas in 2008, along with the electricity price for a range of parameters. ${ }^{16}$ For a wide range of carbon budget and convexity parameter values, the operational LCOE is 2 to 5 times higher for renewable power than for gas. This difference comes from the wrong anticipations one makes when considering only current signals. These are biased toward gas for two reasons: the future increase in fuel and carbon price is not accounted for, and gas is assumed to produce at full capacity for its whole lifetime.

These simulations thus suggest that if an agent was to assess investment in new capacity for the European electricity market by computing LCOEs from current prices, she would recommend to invest too much in gas capacity, and not enough in renewable capacity.

\footnotetext{
${ }^{16}$ Note that computing the LCOE only make sense if investment is strictly positive.
} 


\section{Conclusion}

Our analysis makes several simplifications. For instance, we do not account for knowledge accumulation and directed technical change, which have been found to play a key role in the optimal transition from fossil to renewable energy (Tahvonen and Salo, 2001; Acemoglu et al., 2012; André and Smulders, 2014; Gerlagh et al., 2014). Knowledge spillovers would tend to increase the short-term gap between optimal investment in renewable and gas power (Rosendahl, 2004; del Rio Gonzalez, 2008), adding to the effect of adjustment costs studied here. We also disregarded uncertainty, known to play a key role in optimal accumulation of capital (Pindyck, 1991), optimal emission reduction pathways (Ha Duong et al., 1997), and optimal extraction of several energy sources (Gaudet and Lasserre, 2011). Finally, we did not account for the possibility to retrofit existing plants (notably with carbon capture and storage), and the possibility to use cleaner fuels (in particular derived from biomass) in existing power plants.

Notwithstanding these limitations, our analysis suggests that capacity constraints and adjustment costs play an essential role in the transition from coal to gas and renewable energy. In particular, investment in renewable power should start before coal and gas resources are phased out, and should be higher than investment in gas power. The transition to carbon-free power may nonetheless benefit from temporary investment in intermediate technologies such as gas, to decrease the need for costlier renewable in the short term. The resulting plants would however need to be subsequently decommissioned before the end of their natural lifetime, to give room to more carbon-free power in the medium term.

Our results shed light on technical choices (e.g. investors can consider gas plants with shorter scheduled lifetimes or an option to retrofit) as well as policy decisions (when setting milestones for carbon-free power or managing the social consequences of decommissioning stranded fossil-fueled plants). Moreover, we warn that the levelized cost of electricity (LCOE) computed against current price signals is biased toward gas power and against renewable power. An accurate valuation of different types of power plants requires to anticipate a comprehensive long-term investment and production pathway, and in particular that gas built to replace coal in the short term may itself be replaced with renewable in the medium term.

Finally, while this paper focuses on power generation, it more broadly informs on the ordering and assessment of investment in polluting fossil-fueled and clean capital; its results could be extended to other capitalistic and energyintensive sectors, such as buildings or transportation.

\section{References}

Acemoglu, D., Aghion, P., Bursztyn, L., Hemous, D., 2012. The environment and directed technical change. American Economic Review 102 (1), 131-166.

Allen, M., Frame, D., Huntingford, C., Jones, C., Lowe, J., Meinshausen, M., Meinshausen, N., 2009. Warming caused by cumulative carbon emissions towards the trillionth tonne. Nature 458 (7242), 1163-1166.

Alvarez, R. A., Pacala, S. W., Winebrake, J. J., Chameides, W. L., Hamburg, S. P., 2012. Greater focus needed on methane leakage from natural gas 
infrastructure. Proceedings of the National Academy of Sciences 109 (17), 6435-6440.

Ambec, S., Crampes, C., 2012. Electricity provision with intermittent sources of energy. Resource and Energy Economics 34 (3), 319-336.

Amigues, J.-P., Ayong Le Kama, A., Chakravorty, U., Moreaux, M., 2013. Equilibrium transitions from non renewable energy to renewable energy under capacity constraints. LERNA Working Papers 11.07.341.

Amigues, J.-P., Favard, P., Gaudet, G., Moreaux, M., 1998. On the optimal order of natural resource use when the capacity of the inexhaustible substitute is limited. Journal of Economic Theory 80 (1), 153 - 170.

André, F. J., Smulders, S., 2014. Fueling growth when oil peaks: Directed technological change and the limits to efficiency. European Economic Review.

Arrow, K. J., 1964. Optimal capital policy, the cost of capital, and myopic decision rules. Annals of the Institute of Statistical Mathematics 16 (1), 2130 .

Bazilian, M., Onyeji, I., Liebreich, M., MacGill, I., Chase, J., Shah, J., Gielen, D., Arent, D., Landfear, D., Zhengrong, S., 2013. Re-considering the economics of photovoltaic power. Renewable Energy 53, 329-338.

Cairns, R. D., 1998. The microeconomics of mineral extraction under capacity constraints. Nonrenewable Resources 7 (3), 233-244.

Campbell, H. F., 1980. The effect of capital intensity on the optimal rate of extraction of a mineral deposit. The Canadian Journal of Economics / Revue canadienne d'Economique 13 (2), 349-356.

Chakravorty, U., Moreaux, M., Tidball, M., 2008. Ordering the extraction of polluting nonrenewable resources. The American Economic Review 98 (3), 1128-1144.

Collins, M., Knutti, R., Arblaster, J. M., Dufresne, J.-L., Fichefet, T., Friedlingstein, P., Gao, X., Gutowski, W. J., Johns, T., Krinner, G., 2013. Long-term climate change: projections, commitments and irreversibility. In: Climate Change 2013: The Physical Science Basis. Contribution of Working Group I to the Fifth Assessment Report of the Intergovernmental Panel on Climate Change.

Dasgupta, P., Heal, G., 1974. The optimal depletion of exhaustible resources. The Review of Economic Studies 41, pp. 3-28.

del Rio Gonzalez, P., 2008. Policy implications of potential conflicts between short-term and long-term efficiency in $\mathrm{CO}_{2}$ emissions abatement. Ecological Economics 65 (2), 292-303.

EIA, 2013. Levelized cost of new generation resources in the annual energy outlook 2013. Tech. rep., Energy Information Administration.

ENERDATA, 2012. Global energy \& $\mathrm{CO}_{2}$ database. Consulted May 2012. 
EU, 2011. Impact assessment accompanying the communication from the commission: Energy roadmap 2050. Commission Staff Working Document Sec(2011) 1565 final, European Commission.

Fischer, C., Withagen, C., Toman, M., 2004. Optimal investment in clean production capacity. Environmental and Resource Economics 28 (3), 325-345.

Gaudet, G., 1983. Optimal investment and adjustment costs in the economic theory of the mine. The Canadian Journal of Economics / Revue canadienne d'Economique 16 (1), 39-51.

Gaudet, G., 2014. Modelling the use of nonrenewable resources with multiple demands and multiple sources.

Gaudet, G., Lasserre, P., 2011. The efficient use of multiple sources of a nonrenewable resource under supply cost uncertainty. International Economic Review 52 (1), 245-258.

Gerlagh, R., Kverndokk, S., Rosendahl, K. E., 2014. The optimal time path of clean energy r\&d policy when patents have finite lifetime. Journal of Environmental Economics and Management 67 (1), 2-19.

Golombek, R., Greaker, M., Hoel, M., 2010. Carbon taxes and innovation without commitment. The B.E. Journal of Economic Analysis \& Policy 10 (1).

Gould, J. P., 1968. Adjustment costs in the theory of investment of the firm. The Review of Economic Studies 35 (1), pp. 47-55.

Ha Duong, M., Grubb, M., Hourcade, J.-C., 1997. Influence of socioeconomic inertia and uncertainty on optimal CO2-emission abatement. Nature 390 (6657), $270-273$.

Helm, D., Hepburn, C., Mash, R., 2003. Credible carbon policy. Oxford Review of Economic Policy 19 (3), 438-450.

Herfindahl, O. C., 1967. Depletion and economic theory. Extractive resources and taxation, 63-90.

Holland, S. P., 2003. Extraction capacity and the optimal order of extraction. Journal of Environmental Economics and Management 45 (3), 569-588.

Hotelling, H., 1931. The economics of exhaustible resources. The Journal of Political Economy 39 (2), 175, 137.

IEA, 2010. Projected cost of generating electricity, 2010 edition. Tech. rep., International Energy Agency.

IEA, 2014. Harnessing Electricity's Potential. Energy Technology Perspectives. International Energy Agency.

IPCC, 2014. Technical summary. In: Climate Change 2014: Mitigation of Climate Change. Intergovernmental Panel on Climate Change.

Iyer, G., Hultman, N., Eom, J., McJeon, H., Patel, P., Clarke, L., 2014. Diffusion of low-carbon technologies and the feasibility of long-term climate targets. Technological Forecasting and Social Change (forthcoming). 
Jorgenson, D., 1967. The theory of investment behavior. In: Determinants of investment behavior. NBER, pp. 129-188.

Joskow, P. L., 2011. Comparing the costs of intermittent and dispatchable electricity generating technologies. American Economic Review: Paper and Proceedings 101 (3), 238-41.

Kemp, M. C., Long, N. V., 1980. On two folk theorems concerning the extraction of exhaustible resources. Econometrica 48 (3), 663-673.

Kost, C., Jessica Thomsen, Sebastian Nold, Johannes Mayer, 2012. Levelized cost of electricity renewable energies. Tech. rep., Fraunhofer ISE.

Kriegler, E., Weyant, J. P., Blanford, G. J., Krey, V., Clarke, L., Edmonds, J., Fawcett, A., Luderer, G., Riahi, K., Richels, R., Rose, S. K., Tavoni, M., Vuuren, D. P. v., 2014. The role of technology for achieving climate policy objectives: overview of the EMF 27 study on global technology and climate policy strategies. Climatic Change 123 (3-4), 353-367.

Lasserre, P., 1985. Exhaustible-resource extraction with capital. In: Progress in natural resource economic, oxford: clarendon press, Edition. Anthony Scott, pp. $178-202$.

Loulou, R., 2008. ETSAP-TIAM: the TIMES integrated assessment model. Computational Management Science 5 (1-2), 41-66.

Matthews, H. D., Gillett, N., Stott, P., Zickfeld, K., 2009. The proportionality of global warming to cumulative carbon emissions. Nature 459 (7248), 829-832.

Mussa, M., 1977. External and internal adjustment costs and the theory of aggregate and firm investment. Economica 44 (174), pp. 163-178.

Pindyck, R. S., 1991. Irreversibility, uncertainty, and investment. Journal of Economic Literature 29 (3), 1110-1148.

Rogelj, J., Hare, W., Lowe, J., van Vuuren, D. P., Riahi, K., Matthews, B., Hanaoka, T., Jiang, K., Meinshausen, M., 2011. Emission pathways consistent with a $2^{\circ} \mathrm{C}$ global temperature limit. Nature Climate Change 1 (8), 413-418.

Rosendahl, K. E., 2004. Cost-effective environmental policy: implications of induced technological change. Journal of Environmental Economics and Management 48 (3), 1099-1121.

Rozenberg, J., Vogt-Schilb, A., Hallegatte, S., 2014. Transition to clean capital, irreversible investment and stranded assets. World Bank Policy Research Working Paper (6859).

Seebregts, A., Goldstein, G., Smekens, K., 2002. Energy/environmental modeling with the MARKAL family of models. In: Chamoni, P., Leisten, R., Martin, A., Minnemann, J., Stadtler, H. (Eds.), Operations Research Proceedings 2001. Vol. 2001 of Operations Research Proceedings 2001. Springer Berlin Heidelberg, pp. 75-82.

Slechten, A., 2013. Intertemporal links in cap-and-trade schemes. Journal of Environmental Economics and Management 66 (2), 319-336. 
Smulders, S., van der Werf, 2008. Climate policy and the optimal extraction of high- and low-carbon fossil fuels. The Canadian Journal of Economics / Revue canadienne d'Economique 41 (4), 1421-1444.

Solow, R. M., 1974. Intergenerational equity and exhaustible resources. The Review of Economic Studies 41, 29-45.

Spiro, D., 2012. Resource prices and planning horizons. Mimeo.

Steinacher, M., Joos, F., Stocker, T. F., 2013. Allowable carbon emissions lowered by multiple climate targets. Nature 499 (7457), 197-201.

Stiglitz, J., 1974. Growth with exhaustible natural resources: Efficient and optimal growth paths. The Review of Economic Studies 41, 123-137.

Tahvonen, O., Salo, S., 2001. Economic growth and transitions between renewable and nonrenewable energy resources. European Economic Review 45 (8), $1379-1398$.

Trotignon, R., Delbosc, A., 2008. Échanges de quotas en période d'essai du marche européen du $\mathrm{CO}_{2}$ : ce que révèle le CITL. Etude climat 13, Caisse des dépots, Mission climat.

UE, 2011. A roadmap for moving to a competitive low carbon economy in 2050. Communication from the Commission $\operatorname{COM}(2011) 112$ final, European Commission.

Ueckerdt, F., Hirth, L., Luderer, G., Edenhofer, O., 2013. System LCOE: What are the costs of variable renewables? Energy $63,61-75$.

Ulph, A., Ulph, D., 2013. Optimal climate change policies when governments cannot commit. Environmental and Resource Economics 56 (2), 161-176.

van der Ploeg, F., Withagen, C., 2012. Too much coal, too little oil. Journal of Public Economics 96 (12), 62-77.

van der Ploeg, F., Withagen, C., 2014. Growth, renewables, and the optimal carbon tax. International Economic Review 55 (1), 283-311.

Vogt-Schilb, A., Hallegatte, S., de Gouvello, C., 2014a. Long-term mitigation strategies and marginal abatement cost curves: a case study on Brazil. World Bank Policy Research (6808).

Vogt-Schilb, A., Meunier, G., Hallegatte, S., 2014b. Optimal timing, cost and sectoral dispatch of emission reductions: abatement cost curves vs. abatement capital accumulation.

Waisman, H., Rozenberg, J., Sassi, O., Hourcade, J.-C., 2012. Peak oil profiles through the lens of a general equilibrium assessment. Energy Policy 48, 744753 .

Wang, M., Zhao, J., 2013. Monopoly extraction of a nonrenewable resource facing capacity constrained renewable competition. Economics Letters 120 (3), 503-508. 
Weyant, J. P., 2004. Introduction and overview to the EMF 19 study on technology and climate change policy. Energy Economics 26 (4), 501-515.

Wikibooks contributors, 2014. First order linear 1. In: Ordinary Differential Equations. Wikibooks.

Williams, J. H., DeBenedictis, A., Ghanadan, R., Mahone, A., Moore, J., Morrow, W. R., Price, S., Torn, M. S., 2012. The technology path to deep greenhouse gas emissions cuts by 2050: The pivotal role of electricity. Science 335 (6064), 53-59.

Williams, R., 2010. Setting the initial time-profile of climate policy: The economics of environmental policy phase-ins. Working Paper 16120, National Bureau of Economic Research.

Wilson, C., Grubler, A., Bauer, N., Krey, V., Riahi, K., 2013. Future capacity growth of energy technologies: are scenarios consistent with historical evidence? Climatic Change 118 (2), 381-395.

\section{A. Efficiency conditions}

Table A.5: Variables and parameters notations used in the model.

\begin{tabular}{|c|c|c|}
\hline & Description & Possible units \\
\hline$i$ & technology index & \\
\hline$h$ & high-carbon technology $(h)$ & \\
\hline$l$ & low-carbon technology $(\ell)$ & \\
\hline$z$ & zero-carbon technology $(z)$ & \\
\hline$k_{i, t}$ & capacity of technology $i$ at time $t$ & GW \\
\hline$q_{i, t}$ & production of technology $i$ at time $t$ & GW \\
\hline$x_{i, t}$ & physical investment in technology $i$ at time $t$ & $\mathrm{GW} / \mathrm{yr}$ \\
\hline$\nu_{i, t}$ & shadow price of new capacity $i$ & $\$ / G W$ \\
\hline$\mu_{t}$ & cost of emissions & $\$ / \mathrm{tCO}_{2}$ \\
\hline$\alpha_{i, t}$ & cost of resource used by technology $i$ & $\$ / \mathrm{MWh}$ \\
\hline$\gamma_{i, t}$ & shadow rental cost of existing capacity $i$ & $\$ /(\mathrm{GW} \cdot \mathrm{yr})$ \\
\hline$u_{t}^{\prime}$ & output price & $\$ / G W h$ \\
\hline$c_{i}\left(x_{i, t}\right)$ & monetary investment in technology $i$ at time $t$ & $\$ / y r$ \\
\hline$m_{t}$ & stock of atmospheric carbon & $\mathrm{tCO}_{2}$ \\
\hline$\delta$ & depreciation rate & $\mathrm{yr}^{-1}$ \\
\hline$r$ & discount rate & $\mathrm{yr}^{-1}$ \\
\hline$F_{i}$ & emission rate of technology $i$ & $\mathrm{tCO}_{2} / \mathrm{GWh}$ \\
\hline $\bar{M}$ & carbon budget & $\mathrm{tCO}_{2}$ \\
\hline$u\left(\sum_{i} q_{i, t}\right)$ & consumer utility & $\$ / y r$ \\
\hline
\end{tabular}


The present value Hamiltonian associated with Problem 9 reads:

$$
\begin{aligned}
\mathcal{H}=e^{-r t} & {\left[u\left(\sum_{i} q_{i, t}\right)-\sum_{i} c_{i}\left(x_{i, t}\right)-\sum_{i} \nu_{i, t}\left(\delta k_{i, t}-x_{i, t}\right)\right.} \\
& -\mu_{t} \sum_{i} R_{i} q_{i, t}-\eta_{t}\left(m_{t}-\bar{M}\right)-\sum_{i}\left(\alpha_{i, t} q_{i, t}-\beta_{i, t} S_{i, t}\right) \\
& \left.-\sum_{i} \gamma_{i, t}\left(q_{i, t}-k_{i, t}\right)+\sum_{i} \lambda_{i, t} q_{i, t}\right]
\end{aligned}
$$

The first-order conditions are:

$$
\begin{aligned}
\frac{\partial \mathcal{H}}{\partial x_{i}}=0 & \Longleftrightarrow & c_{i}^{\prime}\left(x_{i, t}\right)=\nu_{i, t} \\
\frac{\partial \mathcal{H}}{\partial q_{i}}=0 & \Longleftrightarrow & \lambda_{i, t}-\mu_{t} R_{i}-\alpha_{i, t}+u_{t}^{\prime}=\gamma_{i, t} \\
\frac{\partial \mathcal{H}}{\partial k_{i}}=\frac{-d\left(e^{-r t} \nu_{i, t}\right)}{d t} & \Longleftrightarrow & (\delta+r) \nu_{i, t}-\dot{\nu}_{i, t}=\gamma_{i, t} \\
\frac{\partial \mathcal{H}}{\partial m_{t}}=\frac{-d\left(e^{-r t} \mu_{t}\right)}{d t} & \Longleftrightarrow & \dot{\mu}_{t}-r \mu_{t}=-\eta_{t} \\
\frac{\partial \mathcal{H}}{\partial S_{i}}=\frac{-d\left(e^{-r t} \alpha_{i, t}\right)}{d t} & \Longleftrightarrow & \dot{\alpha}_{i}-r \alpha_{i, t}=-\beta_{i, t}
\end{aligned}
$$

The complementary slackness conditions are:

$$
\begin{array}{llll}
\forall i, t, & \lambda_{i, t} \geq 0, \quad q_{i, t} \geq 0 & \text { and } & \lambda_{i, t} q_{i, t}=0 \\
\forall i, t, & \eta_{t} \geq 0, \quad \bar{M}-m_{t} \geq 0 & \text { and } & \eta_{t}\left(\bar{M}-m_{t}\right)=0 \\
\forall i, t, & \beta_{i, t} \geq 0, \quad S_{i, t} \geq 0 & \text { and } & \beta_{i, t} S_{i, t}=0 \\
\forall i, t, & \gamma_{i, t} \geq 0, \quad k_{i, t}-q_{i, t} \geq 0 & \text { and } & \gamma_{i, t}\left(k_{i, t}-q_{i, t}\right)=0
\end{array}
$$

The transversality condition is replaced by the terminal condition that at some point the atmospheric carbon reaches its ceiling (6).

\section{B. Investment and production phases}

\section{B.1. Carbon budget constraint and steady state}

Let $T_{\eta}$ be the date when the ceiling on atmospheric carbon is reached. The carbon-free atmosphere can be seen as a non renewable resource depleted by GHG emissions. In this context, the optimal current carbon price follows Hotelling's rule, i.e. grows at the discount rate $r$ (A.5, A.8):

$$
\forall t<T_{\eta}, \quad \mu_{t}=\mu e^{r t}>0
$$

where $\mu$ is the carbon price at $t=0$. Eq. B. 1 reflects the fact that abatement realized at any time contributes equally to meet the carbon budget. We focus on the case where the carbon budget is binding, so that the carbon price $\mu_{t}$ is strictly positive.

Let $T$ be the date when the system reaches a steady state. During the steady state, the clean backstop produces all the output. Indeed, atmospheric carbon 
is stable, hence emissions and production from high- and low-carbon fossil fuels must be nil $(4,6,7)$ :

$$
\forall t \geq T, \dot{m}_{t}=0 \Longrightarrow q_{\ell, t}=q_{h, t}=0
$$

When the carbon budget is binding, the date when the ceiling on atmospheric carbon is reached and the steady state necessarily coincide: $T=T_{\eta}$.

\section{B.2. Output production and fossil fuel deposits}

Initially, all the output is produced from coal by assumption. Coal production is eventually replaced by gas or renewable power. Let $T_{h}^{-}$be the date when high-carbon production stops:

$$
\forall t \geq T_{h}^{-}, q_{h, t}=0
$$

This happens necessarily before the steady state:

$$
T_{h}^{-} \leq T
$$

Similarly, let $T_{i}^{+}$be the date when production of technology $i \in\{\ell, z\}$ starts, and $T_{\ell}^{-}$the date when gas production stops. Note that only low-carbon production eventually stops, since zero-carbon energy is used indefinitely during the steady state. ${ }^{17}$

Let $T^{\beta}$ be the date when the low-carbon fossil fuel deposit is depleted. If it exists (i.e. if the gas deposit is eventually depleted), $T^{\beta}$ coincides with the end of production from low-carbon fuel:

$$
\exists T^{\beta} \Longrightarrow T_{\ell}^{\beta}=T_{\ell}^{-}
$$

Optimality then requires that fossil fuel prices follow the Hotelling rule: their current price $\alpha_{\ell, t}$ is increasing at the discounting rate before they are exhausted (A.6, A.9):

$$
\forall t<T^{\beta}, \alpha_{\ell, t}=\alpha_{\ell} e^{r t}>0
$$

\section{B.3. Investment and under-utilization of capacities}

For coal to be phased out, production in one of the alternative technologies must have started:

$$
T_{h}^{-} \geq \min \left(T_{\ell}^{+}, T_{z}^{+}\right)
$$

Let $\tau_{i}^{+} \leq T_{i}^{+}$be the date when investment in capacity $i$ starts, and $\tau_{i}^{-}$the date when it stops. Note that only the investment in gas stops eventually, since renewable capacity is used indefinitely during the steady state and must be maintained as $\delta>0$.

If gas is used during the transition, production from gas must decline before the steady state, either because gas reserves are depleted, or to reduce GHG emissions to zero. If it declines faster than the depreciation rate of capacities,

\footnotetext{
17 As the marginal utility tends to infinity when energy consumption tends to zero energy production is always strictly positive.
} 
installed gas capacities may be underused. Let $T_{\gamma} \in\left[T_{\ell}^{+}, T_{\ell}^{-}\right]$be the date when gas production is lower than its capacity:

$$
\forall t \geq T_{\gamma}, k_{\ell, t}>0 \Longrightarrow q_{\ell, t}<k_{\ell, t}
$$

The social planner stops to invest in gas power plants when the marginal cost of new capacities exceeds its marginal benefit:

$$
c_{\ell}^{\prime}(0)=\int_{\tau_{\ell}^{-}}^{T_{\gamma}} e^{-(r+\delta)\left(\theta-\tau_{\ell}^{-}\right)}\left(u_{\theta}^{\prime}-\mu_{\theta} F_{i}-\alpha_{i, \theta}\right) d \theta
$$

such that in general she stops investing before starting to underuse gas capacities

$$
\tau_{\ell}^{-} \leq T_{\gamma}
$$

In particular, if $c_{\ell}^{\prime}(0)=0$ then $\tau_{\ell}^{-}=T_{\gamma}$ (this is the case in Fig. 3 ).

We assume that coal capacity is overabundant at the beginning of the transition, meaning that its capacity is underused from the start. In other words, coal is marginal during the first phase of the transition. As two technologies cannot be marginal at the same time (Lemma 1), gas can be the marginal technology (and gas capacity gets underused) only after coal is completely phased out:

$$
T_{h}^{-} \leq T_{\gamma} \leq T_{\ell}^{-}
$$

If gas is used, it's thus used from the moment there are some gas capacities

$$
\exists\left(T_{\ell}^{+}, \tau_{\ell}^{+}\right) \Longrightarrow T_{\ell}^{+}=\tau_{\ell}^{+}
$$

B.11 also means that if gas is used, once gas production ends, coal production has ended, and emissions are null. The end of gas production thus coincides with the steady state:

$$
\exists T_{\ell}^{-} \Longrightarrow T_{\ell}^{-}=T
$$

If production does not decrease with time, the moment when gas starts being underused necessarily happens after wind started to produce:

$$
T_{z}^{+} \leq T_{\gamma}
$$

Finally, because variable costs from renewable are nil, its never optimal not to use renewable at full capacity:

$$
T_{z}^{+}=\tau_{z}^{+}
$$

\section{B.4. Summary of the transition phases}

This leaves us with three possible transition profiles:

1. Two successive transitions. Gas first completely replaces coal, then renewable power replaces gas.

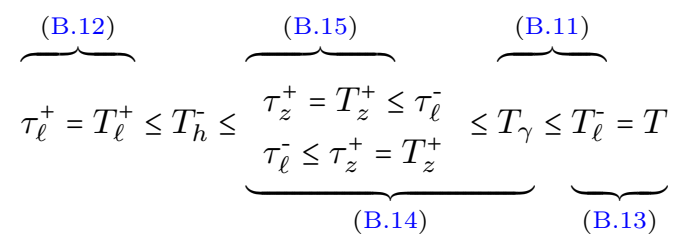


Table B.6: Parameters used to produce Fig. 2

\begin{tabular}{|c|c|c|c|c|c|c|c|}
\hline & Fig. 2c & Fig. 2b & Fig. 2a & & Fig. 2c & Fig. 2b & Fig. 2a \\
\hline$\delta$ & .0333 & .0333 & .0333 & $\alpha_{z}$ & 0 & 0 & 0 \\
\hline $\bar{M}$ & 42 & 38 & 40 & $\alpha_{h}$ & .055 & .055 & .055 \\
\hline$D$ & 1940 & 1940 & 1940 & $\alpha_{\ell}$ & .1 & .06 & .06 \\
\hline$r$ & .05 & .05 & .05 & $C_{z}^{m}$ & 75000 & 75000 & 80000 \\
\hline$R_{z}$ & 0 & 0 & 0 & $C_{h}^{m}$ & 18000 & 18000 & 18000 \\
\hline$R_{h}$ & .00063 & .00063 & .00063 & $C_{\ell}^{m}$ & 35000 & 12000 & 12000 \\
\hline$R_{\ell}$ & .0004 & .0004 & .0003 & $X_{z}$ & .00003 & .0005 & .001 \\
\hline$H_{z}$ & 7500 & 7500 & 7500 & $X_{h}$ & .005 & .005 & .005 \\
\hline$H_{h}$ & 7500 & 7500 & 7500 & $X_{\ell}$ & .0001 & .001 & .01 \\
\hline \multirow[t]{2}{*}{$H_{\ell}$} & 7500 & 7500 & 7500 & $A$ & .9 & .9 & .9 \\
\hline & & & & $I$ & 12 & 12 & 2 \\
\hline
\end{tabular}

2. Gas and wind simultaneously replace coal, starting with gas.

$$
\underbrace{\tau_{\ell}^{+}=T_{\ell}^{+}}_{\text {(B.12) }} \leq \underbrace{\tau_{z}^{+}=T_{z}^{+}}_{\text {(B.15) }} \leq \overbrace{\begin{array}{l}
T_{h}^{-} \leq \tau_{\ell}^{-} \\
\tau_{\ell}^{-} \leq T_{h}^{-}
\end{array} \underbrace{T_{\gamma} \leq T_{\ell}^{-}}_{\text {(B.11) }}=T}^{(\text {B.10,B.11) }}
$$

3. Gas and wind simultaneously replace coal, starting with renewable power.

$$
\underbrace{\tau_{z}^{+}=T_{z}^{+}}_{\text {(B.15) }} \leq \underbrace{\tau_{\ell}^{+}=T_{\ell}^{+}}_{\text {(B.12) }} \leq \overbrace{\begin{array}{l}
T_{h}^{-} \leq \tau_{\ell}^{-} \\
\tau_{\ell}^{-} \leq T_{h}^{-}
\end{array} \underbrace{T_{\gamma} \leq T_{\ell}^{-}}_{(\text {B.11) }}=T}^{(\text {B.10,B.11) }} \overbrace{}^{\text {B.13) }}
$$

Fig. 2 illustrates the three possible transition profiles, by using the parameters gathered in Table B.6 and the following cost function:

$$
c_{i}^{\prime}\left(x_{i, t}\right)=C_{i}^{m} \cdot A \cdot I+C_{i}^{m} \cdot(1-A) \frac{x_{i, t}}{X_{i}}
$$

